\title{
Diacronie
}

Studi di Storia Contemporanea

$\mathrm{N}^{\circ} 32,4 \mid 2017$

Proiezioni individuali e agire collettivo nella storia

\section{Considerazioni introduttive. Laboratorio n. 32 - dicembre 2017}

\section{Arianna Pasqualini e Irene Vascelli}

\section{(2) OpenEdition}

1 Journals

Edizione digitale

URL: http://journals.openedition.org/diacronie/6718

DOI: $10.4000 /$ diacronie. 6718

ISSN: 2038-0925

Editore

Association culturelle Diacronie

Notizia bibliografica digitale

Arianna Pasqualini e Irene Vascelli, «Considerazioni introduttive. Laboratorio n. 32 - dicembre 2017 », Diacronie [Online], № 32, 4 | 2017, Messo online il 29 décembre 2017, consultato il 24 septembre 2020. URL : http://journals.openedition.org/diacronie/6718; DOI : https://doi.org/10.4000/diacronie.6718

Questo documento è stato generato automaticamente il 24 settembre 2020.

Creative Commons License 


\section{Considerazioni introduttive. Laboratorio n. 32 - dicembre 2017}

Arianna Pasqualini e Irene Vascelli

Da prostitute a sex workers

Il dibattito europeo sulla regolamentazione della prostituzione 
«Battersi per i diritti delle prostitute significa battermi per i miei diritti di lavoratrice. Poter scegliere un lavoro senza essere soggetta a sfruttamento e violenza. Essere, in pratica, riconosciuta come una cittadina di serie $A »^{1}$. Così Pia Covre, prostituta e attivista italiana, si espone in difesa dei diritti civili delle lavoratrici del sesso, da sempre sottoposte allo stigma sociale. Le prime interpretazioni sulla prostituzione risalgono alla morale cristiana, che considerava questo commercio come deviante e immorale. In quest'ottica i piaceri del corpo non erano altro che la conseguenza del peccato originale, dunque le donne che vendevano sesso sporcavano con il denaro la purezza dei rapporti sessuali destinati alla procreazione.

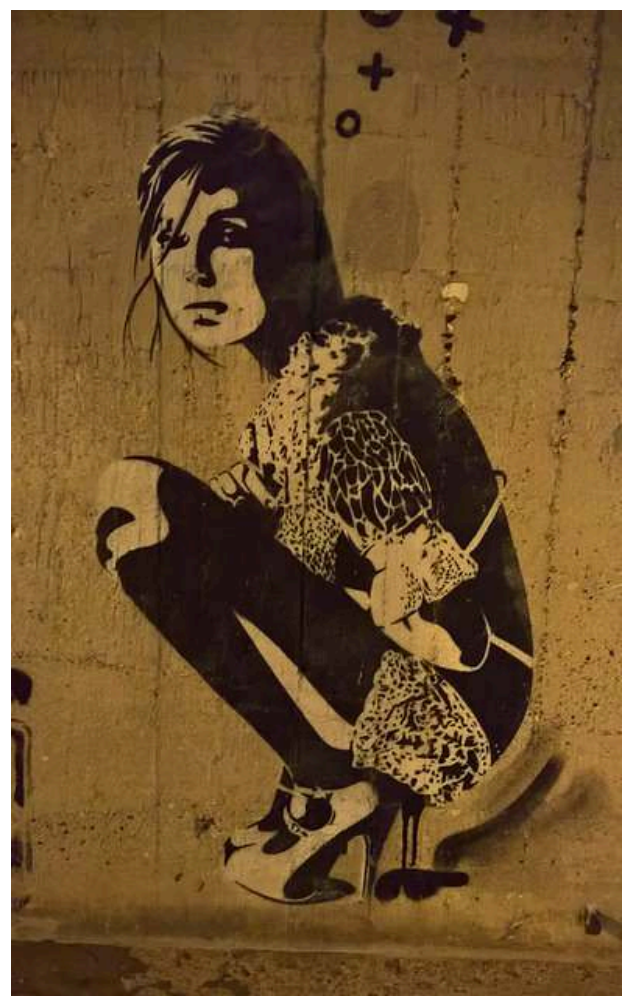

2 Tuttavia se da una parte tale pratica era considerata immorale per le donne, dall'altra era considerata un "male necessario" per gli uomini. Secondo la teoria dei quattro umori di Galeno, infatti, lo spirito maschile era equilibrato solo espellendo lo sperma, che se mantenuto troppo nel corpo avrebbe creato malessere fisico e spirituale nell'individuo. La donna invece, che espelleva gli umori negativi con il ciclo mestruale, non aveva bisogno di rapporti sessuali al di là di quelli destinati al concepimento. Paradossalmente la figura della prostituta ha sempre svolto un ruolo necessario per la società, ma allo stesso tempo è stata considerata una devianza dall'essere donna in senso ontologico, poiché si discostava dal modello di femminilità socialmente imposto.

3 In quanto considerate devianti e psicologicamente instabili, le prostitute non hanno mai avuto, se non in casi sporadici, la possibilità di autodeterminarsi e di influenzare le leggi riguardanti il loro mestiere. La svolta avviene soltanto tra gli anni Settanta e Ottanta del Novecento. Infatti, parallelamente alle lotte femministe e alla rivendicazione di un nuovo ruolo sociale per la donna, libero dall'egemonia del padrepadrone, inizia a maturare una certa coscienza politica da parte delle prostitute, che cominciano ad associarsi in organizzazioni per far sentire anche la propria voce.

4 Alla nascita del primo movimento delle prostitute (COYOTE - Call Off Your Tired Ethics), avvenuta negli Stati Uniti del 1973, seguì infatti una diffusione capillare anche in Europa di movimenti mossi dagli stessi obiettivi: Les Putes in Francia, English Collective of Prostitute in Inghilterra ed il Comitato per i Diritti Civili delle Prostitute in Italia ${ }^{2}$. In questo contesto la prostituta diviene soggetto politico e si fa portavoce di una rivoluzione culturale che ha come punto di partenza lo stravolgimento del linguaggio, attraverso la rinuncia al concetto di "vittima" e la modifica del termine "prostituta" in sex worker. Ad utilizzare per prima questa denominazione fu Carol Leigh ${ }^{3}$, prostituta e attivista del gruppo COYOTE, che con "sex work" intendeva riferirsi alle prostitute e alle lavoratrici dell'industria del sesso. Associare al concetto di sesso (sex) quello di lavoro 
(work) e auto-definirsi lavoratrici aveva lo scopo di privare il lavoro sessuale della connotazione negativa a cui si accompagnava ${ }^{4}$.

Lo stesso pensiero è stato portato avanti da Roberta Tatafiore, giornalista, attivista, fervente femminista, poetessa, fondatrice, insieme a Maria Adele Teodori, del mensile «Lucciola», che formula una visione della prostituzione in termini di mercato, in cui il sex work risulta essere un'alternativa come un'altra ${ }^{5}$. Il mercato della prostituzione risulta dunque essere, ci dice la Tatafiore, il risultato dell'era della globalizzazione e la prostituta, chiamata appunto ora sex worker, emerge in quanto figura portatrice di competenze, come soggetto che preferisce il marciapiede alla fabbrica e che rivendica la libertà di tale scelta. Il lavoro sessuale non determina dunque l'essenza di una persona, ma dovrebbe essere considerato una pura mansione, svolta con il solo scopo di guadagnarsi da vivere: «Sex work is something you do, not something you are», come sostengono le sex workers svedesi del comitato di Rose Alliance.

Nonostante la presa di coscienza delle lavoratrici sessuali, la strada per l'acquisizione dei loro diritti appare ancora lunga e tortuosa a causa delle norme legislative non corrispondenti alle loro richieste, ma anche a causa dell'opinione pubblica e talvolta dei movimenti femministi, poco solidali nei confronti delle associazioni di sex workers. Risulta dunque evidente come per comprendere il fenomeno sia necessario analizzarlo da diversi punti di vista. Negli articoli che seguiranno si analizzeranno pertanto i percorsi legislativi intrapresi da alcuni paesi europei (Svezia, Germania, Francia, Italia) con un'attenzione particolare agli sviluppi più recenti, valutando il loro impatto sociale e i dibattiti scaturiti. Verranno prese in considerazione sia le opinioni dei sex workers, sia la reazione dei movimenti femministi analizzando, infine, come un argomento così delicato ha portato addirittura ad una frattura ideologica all'interno del mondo femminista.

\section{NOTE}

1. PALLADINI, Federica, «Prostitute e diritti: Intervista a Covre Pia», in Elle, 3 novembre 2011, URL: < http://www.elle.it/magazine/news/a841778/prostitute-diritti-pia-covre/ > [consultato il 23 agosto 2017].

2. Cfr. SELMI, Giulia, Sex work. Il farsi lavoro della sessualità, Bologna, Bébert edizioni, 2016, pp. 42-43.

3. Cfr. Ibidem, p. 46.

4. Cfr. "The Etymology of the terms "Sex Work" and "Sex Worker"», in Sex workers Education Network, URL: < http://www.bayswan.org/sexwork-oed.html\#1 > [consultato il 23 agosto 2017].

5. Cfr. TATAFIORE, Roberta, Sesso al lavoro. La prostituzione al tempo della crisi, Milano, il Saggiatore, 2012. 


\section{AUTORI}

\section{ARIANNA PASQUALINI}

Arianna Pasqualini ha studiato Lettere Moderne presso l'Università di Bologna, dove ha conseguito la laurea triennale nel 2016 con una tesi dal titolo Alterità africane nell'immaginario occidentale del secondo Novecento: voci di una letteratura italiana tra coloniale e neocoloniale. Iscritta a Studi orientali nello stesso ateneo, attualmente partecipa al Master in African Studies presso la Dalarna University a Falun, in Svezia.

URL: < http://www.studistorici.com/progett/autori/\#Pasqualini >

\section{IRENE VASCELLI}

Irene Vascelli ha conseguito la Laurea Triennale in Lettere presso l'Università di Parma con una tesi di laurea in Teoria della Letteratura dal titolo José Saramago e la rilevanza simbolica dei luoghi. Attualmente frequenta il corso di Laurea Magistrale in Scienze storiche e orientalistiche presso l'Università di Bologna.

URL: < http://www.studistorici.com/progett/autori/\#Vascelli > 